\title{
Current Medical and Surgical Options for Androgen Deprivation in Prostate Cancer Patients
}

\author{
Soley Bayraktar ${ }^{1, *}$ and May Abdel-Wahab ${ }^{2}$ \\ ${ }^{I}$ Univeristy of Miami, Sylvester Cancer Center, Hematology/Oncology, Miami, FL, USA \\ ${ }^{2}$ University of Miami, Sylvester Cancer Center, Radiation Oncology, Miami, FL, USA
}

\begin{abstract}
The growth of prostate cancer cells is driven by androgens. Thus, androgen deprivation, is one of the main treatment modalities in the management of prostate cancer. Historically, bilateral orchiectomy, which achieves $95 \%$ reduction of testosterone levels within 3 hours, was the only effective androgen deprivation therapy (ADT). In the 1980s, luteinizing hormone-releasing hormone agonists (LHRH-A) were introduced to reduce testosterone to castration levels. After the 1980s, nonsteroidal antiandrogens were developed in addition to steroidal antiandrogens. Since then, so-called maximum androgen blockade (MAB)/combined androgen blockade (CAB), which is a combination of surgical or medical castration and oral antiandrogens, has been suggested. More recently, novel treatment modalities have been developed, such as intermittent androgen suppression (IAS), nonsteroidal antiandrogen monotherapy, and alternative antiandrogen therapy after relapse from the initial MAB/CAB. ADT, whether surgical or medical, provides important quality of life (QOL) benefits in patients with advanced and metastatic prostate cancer. While the principle of the therapy has remained unchanged, the role, type and timing of these therapies is continuously evolving.

This review will focus on the current medical and surgical options for ADT in advanced and metastatic prostate cancer, summarizing the results of several recent clinical trials and discuss their implications for clinical practice and for future research in this disease.
\end{abstract}

Keywords: Prostate cancer, castration, androgen deprivation therapy, castration, outcome.

\section{INTRODUCTION}

The testes are the major source of testosterone in men. The remaining androgens originate from the adrenal gland hormone precursors that are enzymatically converted to testosterone and dihydrotestosterone in prostatic and peripheral tissues. The growth of prostate cancer cells is driven by androgens [1].

Thus, androgen deprivation, is one of the main treatment modalities in the management of prostate cancer. Historically, bilateral orchiectomy, which achieves $95 \%$ reduction of testosterone levels within 3 hours, was the only effective androgen deprivation therapy (ADT) [2]. Estrogens have been proven equally effective as orchiectomy in treating advanced prostate cancer. However, orchiectomy was irreversible; and estrogen therapy was associated with significant cardiovascular morbidity and even mortality [3]. In the 1980 s, luteinizing hormone-releasing hormone agonists (LHRH-A), later called gonadotropin releasing hormone agonists (GnRH-A), were introduced to reduce testosterone to castration levels [4]. After the 1980s, nonsteroidal antiandrogens were developed in addition to steroidal antiandrogens [4]. Since then, so-called maximum androgen blockade (MAB)/combined androgen blockade $(\mathrm{CAB})$, which is a combination of surgical or medical castration and oral

*Address correspondence to this author at the $1475 \mathrm{NW}$ 12th Ave, Suite 3300, Miami, FL, 33136, USA; Tel: 001-305-458-0999; Fax: 001-305-2431145; E-mail: sbayraktar@med.miami.edu antiandrogens, has been suggested. More recently, novel treatment modalities have been developed, such as intermittent androgen suppression (IAS), nonsteroidal antiandrogen monotherapy, and alternative antiandrogen therapy after relapse from the initial MAB/CAB. While the principle of the therapy has remained unchanged, the role, type and timing of these therapies are continuously evolving.

\section{ADT IN PROSTATE CANCER: A BRIEF OVERVIEW}

Today, in addition to its well-established role in treating patients with metastatic disease, ADT is increasingly used as adjunct therapy for patients undergoing radiation therapy for high-risk, localized disease, locally-advanced disease or lymph-node positive disease treated with radical prostatectomy $[5,6]$.

ADT, whether surgical or medical, provides important quality of life (QOL) benefits in patients with advanced and metastatic prostate cancer. The benefits include but not limited to, decreased rates of spinal cord compression, ureteric obstruction, extraskeletal metastases and pathological fractures $[7,8]$. On the other hand, it is not clear whether there is an improvement in overall survival (OS) in patients with metastatic prostate cancer [9].

The principle in ADT is, to achieve serum testosterone concentrations as low as possible to minimize stimulation of prostate cancer cells. Serum testosterone concentrations that correspond to castration levels have generally been set at less 
$<50 \mathrm{ng} / \mathrm{dL}$ (1.7 nmol/L) [10]. However, most men achieve levels below $20 \mathrm{ng} / \mathrm{dL}(0.7 \mathrm{nmol} / \mathrm{L})$ after orchiectomy, and it has been suggested that castration levels should be redefined to reflect this threshold [11]. Unfortunately, decreased testosterone levels are well known with their short-term and longterm adverse effects including hot flashes, loss of libido, loss of muscle mass, fatigue, gynecomastia, cognitive dysfunction, depression, increased risk of fracture, increased incidence of osteoporosis, diabetes, cardiovascular morbidity and mortality [12-14].

\section{MEDICAL VERSUS SURGICAL CASTRATION}

\section{Effects on Survival}

Common methods of ADT include orchiectomy or medical castration via administration of GnRH-A. Orchiectomy is a relatively simple procedure with minor surgical risks and low physical morbidity; however it has fallen out of favor given its psychological impact and the availability of viable medical alternatives for androgen deprivation. Leuprolide and goserelin are two commonly used GnRH-A and are administered in the form of depot injections or subcutaneous implants.

While GnRH-A are more widely used and accepted by patients than orchiectomy, the question remains as to whether they are as effective. Seidenfeld et al. [15] identified 5 large randomized studies that compared GnRH-A to orchiectomy and none of the 5 studies showed a statistically significant difference in OS among the treatments. The same authors also performed a meta-analysis of data from 12 studies (involving 1539 patients in all) comparing GnRH-A and orchiectomy. No significant differences were found between GnRH-A therapy and orchiectomy in terms of OS, time to progression (TTP) and time to treatment failure (TTF).

\section{EFFECTS ON TESTOSTERONE LEVELS}

Another way of comparing the efficacy of different approaches in ADT is to compare the extent of testosterone suppression. Indeed, Morote et al. [16] reported that DFS was significantly related to testosterone levels ( $>$ or $<32$ ng/dL) during ADT in patients with non-metastatic prostate cancer (mean DFS 88 vs 137 months, $P<0.03$ ). After orchiectomy, patients achieve rapid suppression of serum testosterone levels $<20 \mathrm{ng} / \mathrm{dL}$ within $3-12$ hours [2]. This is accompanied by a decrease in PSA levels to $<10 \mathrm{ng} / \mathrm{mL}$ by 21 days after orchiectomy [17]. By contrast, GnRH-A initially cause testosterone levels rise to a peak, 1.5-2 times greater than the initial testosterone levels; the phenomenon called "testosterone surge" or "flare" reaction [18]. Testosterone levels then remain above baseline levels for 7 days and do not reach castration levels until 3 weeks after administration of the GnRH-A. As a result, serum PSA levels are not effectively suppressed until at least 4 weeks after administering the GnRH-A. Therefore, it is recommended that patients with metastatic disease start with an androgen antagonist prior to initiation of treatment with a GnRH-A and continue for 2 to 4 weeks to block the effect of the testosterone surge and flare reactions.

The degree of testosterone suppression achieved can vary and a significant proportion of patients receiving GnRH-A may not achieve testosterone level of $<20 \mathrm{ng} / \mathrm{dL}$. For example, in one study [18] in which patients received leuprolide acetate, measurement of serum testosterone at 29 days after administration showed that $34 \%$ of patients had testosterone levels of $\geq 20 \mathrm{ng} / \mathrm{dL}$. Similarly, Morote et al. [19] assessed serum testosterone levels in patients treated with 3-monthly GnRH-A injections and found that $37.5 \%$ of patients had testosterone levels of $\geq 20 \mathrm{ng} / \mathrm{dL}$.

A further consideration is whether testosterone suppression is maintained during therapy. Several authors have reported 'breakthroughs' in testosterone suppression in some patients [20-22]. In a long-term follow-up of 62 patients who had received a 3-month leuprolide depot, Jocham [20] reported increases in testosterone to $>50 \mathrm{ng} / \mathrm{dL}$ in four $(6.5 \%)$, while in a larger study (120 men), there were 'breakthroughs' in five (4\%) of patients receiving a 3-month goserelin acetate depot [22]. Also, the study conducted by Tombal and Berges [23, 24] showed that $28-37 \%$ of patients receiving goserelin did not achieve or maintain testosterone levels $<20 \mathrm{ng} / \mathrm{dl}$ at 84 weeks.

These studies all used $50 \mathrm{ng} / \mathrm{dL}$ as a definition for 'breakthrough'. It seems likely that if the threshold had been defined as $20 \mathrm{ng} / \mathrm{dL}$, the rate of breakthrough would have been considerably higher. Taken together, these data suggest that there might be significant shortcomings associated with current GnRH-A, which could affect the long-term outcome of therapy. These data also suggest that GnRH-A are largely used rather than orchiectomy because of patient preference and acceptability, rather than better clinical efficacy.

\section{COST ISSUES RELATED TO ADT ADMINISTRA- TION}

An interesting analysis by Weight et al. [25] in 2008 has revealed that the administration of either surgical or medical castration in the U.S. Medicare population appears to be tied closely to reimbursement in trend. According to the dataset Medicare Part B Extract Summary from 2001 to 2005, the use of medical castration increased from 2001 to 2003, whereas, over the same period, surgical castration decreased. Expenditures related to the use of medical ADT led in part to the Medicare Modernization Act (MMA) in 2003. After the enactment of the MMA, surgical castration rates increased, and medical castration decreased. Total allowed charges for medical castration in 2005 dropped $65 \%$ from the 2003 peak at $\$ 1.23$ billion. These results suggest that mandated decline in reimbursement has affected the way practitioners administer ADT.

In a recent analysis [26] by using the Surveillance, Epidemiology, and End Results (SEER) Medicare database of 82,375 prostate cancer patients (1992-2002), authors have shown that use of ADT varies by the characteristics of the urologists. The analysis showed that the likelihood of ADT use was significantly greater for patients who saw urologists without an academic affiliation. Surprisingly, patients of non-academically affiliated urologists were significantly more likely to receive primary ADT for localized prostate cancer, a setting in which the benefits are uncertain. In this study, trends in medical versus surgical ADT in relation to the characteristics of urologists have not been analyzed. 


\section{DEVELOPMENTS IN MEDICAL ADT}

Faced with the shortcomings of current GnRH-A, there is a need to develop agents that produce rapid, profound and sustained suppression of testosterone without a testosterone flare reactions.

\section{A. New Depot Formulations of GnRH Agonists}

An extended-release depot formulation of leuprolide has been developed: leuprolide acetate for injectable suspension (Eligard ${ }^{\circledR}$, Sanofi Aventis). The drug is administered via an original delivery system that delivers the dose of 7.5 and $22.5 \mathrm{mg}$ of leuprolide during a 1- and 3-month period, respectively [27, 28]. It delivers a twofold higher quantity of LHRH agonist than other depot formulations. Several trials have assessed the pharmacological kinetics, efficacy and safety of this novel LHRH compound [27, 28]. Tombal and Berges showed that with Eligard, serum testosterone peaked at the second day, but decreased thereafter to castration levels of testosterone [23, 24]. By day 28, 98\% of patients reached a castration level of $50 \mathrm{ng} / \mathrm{dl}$, and $84 \%$ reached levels $<20 \mathrm{ng} / \mathrm{dl}$. At the end of the 6-month period, $94 \%$ of patients who completed this study achieved testosterone levels $<20 \mathrm{ng} / \mathrm{dl}$. The mean PSA level decreased by $>98 \%$ from baseline after 6 months of depot therapy with $22.5 \mathrm{mg}$ dose [23]. The increased availability of leuprolide acetate over a prolonged period probably explains the testosterone suppression enhancement compared with the other LHRH conventional depot formulations. The potential advantages of this new compound are that it achieves castration levels more rapidly, and that the threshold of $20 \mathrm{ng} / \mathrm{dl}$ is reached in a larger proportion of patients than with usual depot formulations.

\section{B. GnRH Antagonist Therapy}

In contrast to agonists, GnRH antagonists bind immediately and competitively to GnRH receptors leading to direct pituitary suppression therefore they are not associated with flare reactions. Competitive blocking of the GnRH receptor results in a rapid, but reversible, decrease in LHRH, FSH and testosterone levels [29]. Within $8-24 \mathrm{~h}$ after the initial dose, LHRH and FSH concentrations are reduced by 51$84 \%$ and $17-42 \%$, respectively [29]. The theoretical advantages of GnRH antagonists compared with agonists include: i) no flare reactions; ii) rapid down regulation of $\mathrm{GnRH}$ membrane receptors; iii) no need for combination therapy with an antiandrogen, resulting in improved compliance and fewer side effects; iv) more targeted therapy, including direct action on the primary and secondary tumor cells; v) reduced costs; and vi) more pronounced down regulation of testosterone [30]. GnRH antagonists are indicated for palliative treatment of men with advanced symptomatic prostate cancer, in whom GnRH-A therapy alone is not appropriate because of an initial increase in testosterone, who refuse surgical castration, and who have one or more of the following: (1) risk of neurological compromise due to metastases; (2) ureteral or bladder outlet obstruction due to local encroachment or metastatic disease; or (3) severe bone pain from skeletal metastases persisting with narcotic analgesia use [30].
The reason why GnRH antagonists have not become a mainstay treatment in prostate cancer is because many of the first- and second-generation antagonists are associated with significant histamine-mediated allergic reactions of urticaria, pruritis, hypotension, syncope and $3.7 \%$ incidence of anaphylaxis. The cumulative risk increases with the duration of treatment. Several third and fourth-generation GnRH antagonists have been developed with fewer side effects and are currently under clinical investigations (abarelix, acyline, teverelix, getrorelix, degarelix, ganirelix, iturelix, orntide) [30].

In a Phase II open-label study by Tomera et al. [31], the efficacy of abarelix compared to GnRH-A has been investigated in 242 patients. None of the patients treated with abarelix had testosterone flare during the first week, compared with $82 \%$ of those treated with GnRH-A. During the first week, medical castration was achieved in $75 \%$ of patients in the abarelix group, but none of the patients in GnRH-A group achieved castration. PSA decline was quicker and without flare in the abarelix group. Another randomized study by Trachtenberg et al. [32] compared abarelix to a combination of leuprolide and bicalutamide in 255 patients. Abarelix was more effective in avoiding testosterone surge and showed faster reduction in hormone levels than the combination therapy.

Recently, degarelix has been approved in the US, as a second GnRH antagonist after abarelix, for the treatment of advanced prostate cancer. Initially, preclinical study in rats suggested that rapid, profound and sustained testosterone suppression achieved with degarelix might result in greater suppression of tumor growth than is achieved with GnRH-A $[33,34]$. Those promising results have led to phase II/III clinical studies. The results of phase II studies showed that approximately $90 \%$ of patients receiving degarelix at a dose of $240 \mathrm{mg}$ achieved suppression of testosterone to $\leq 50$ $\mathrm{ng} / \mathrm{dL}$ by day 3 , with no testosterone flare, and that up to $96 \%$ of patients achieving this level of suppression by 28 days had sustained suppression over a year of monthly maintenance therapy [35].

A randomized, open-label, Phase III study to evaluate the efficacy of degarelix versus leuprolide for achieving and maintaining testosterone suppression in patients with prostate cancer over 1 year period was published [33]. Patients were randomized to one of the 3 treatment arms: Arm A, degarelix $240 \mathrm{mg}$ as initial dosage followed by $80 \mathrm{mg}$ monthly; Arm B, degarelix $240 \mathrm{mg}$ as initial dosage followed by $160 \mathrm{mg}$ monthly; Arm C, leuprolide $7.5 \mathrm{mg}$ monthly. The number of patients who achieved medical castration were 202/207 (97\%), 199/202 (98\%) and $194 / 201(96 \%)$ in the degarelix $240 / 80$ and $240 / 160$ and leuprolide groups, respectively. At day 3, 96.1\% and 95.5\% of patients treated with degarelix $240 / 80$ and $240 / 160$ had a testosterone level $\leq 0.5 \mathrm{ng} / \mathrm{ml}$. By contrast, none of the patients in the leuprolide group achieved this result. In fact, the testosterone level in the latter group increased by $65 \%$ (median level $6.3 \mathrm{ng} / \mathrm{ml}, \mathrm{p}<0.001$ ). Between days 28-364, the median testosterone levels were $0.082,0.088$ and 0.078 $\mathrm{ng} / \mathrm{ml}$ in the two degarelix and leuprolide groups [33]. 
At days 14 and 28, PSA declined from baseline by $64 \% / 85 \%$ and $65 \% / 83 \%$ in the $240 / 80$ and $240 / 160$ degarelix groups compared with $18 \% / 68 \%$ in the leuprolide group ( $\mathrm{p}<$ 0.001 ). Following degarelix, median LH and FSH concentrations decreased rapidly and continued to be suppressed until the end of study. At the end of the study mean FSH concentrations decreased by $88.5 \%$ in degarelix $240 / 80 ; 89 \%$ in degarelix 240/160, and 54.8\% in leuprolide 7.5 groups compared to baseline [33]. In the leuprolide group, 44/178 (81\%) of patients who did not receive bicalutamide had a testosterone surge compared to $0 \%$ of patients in the degarelix groups [33]. However, $4 \%$ of patients who received degarelix had chills, compared with none of the patients who received leuprolide.

As a result of these trials, an initial dose of $240 \mathrm{mg}$ followed by a maintenance dose of $80 \mathrm{mg}$ and $160 \mathrm{mg}$ every 4 weeks seems to be best in achieving a profound and sustained testosterone suppression [33]. However, most patients with prostate cancer receiving GnRH-A are treated with a 3month formulation. Therefore, it is a clear disadvantage that degarelix is at present available only as a 1-month formulation. Nevertheless, degarelix which offers better efficacy and adverse effect profile seems to be the most promising agent in this class to date.

A new isoform of GnRH, GnRH-I, has been identified. GnRH-I is synthesized in the hypothalamus, and GnRH-II is widely expressed in the brain, as well as in the peripheral reproductive and immune tissues [36, 37]. GnRH-I stimulates the secretion of pituitary gonadotropins, LHRH and FSH, which, in turn, modulates the synthesis and secretion of androgens from the testis. Studies have demonstrated direct action of GnRH-I on prostate cancer cells. GnRH-I agonists induce a direct inhibitory action on EGF or IGF-induced prostate cancer cell proliferation [38]. The discovery of the GnRH-II isoform raised the question as to whether this isoform is likely to have a diverse functional activity than GnRH-I in prostate cancer cells. For example, in human endometrial and ovarian cancer cells, GnRH-II seems to be a more potent inhibitor of cell proliferation compared to GnRH-I [31]. A recent study by Hurkadli et al. [39] showed that androgen-independent prostate cancer cells bind to GnRH-II with a higher affinity than GnRH-I. Nevertheless, the involvement of GnRH-II and its receptor in prostate cancer cell proliferation is not yet established.

The same study by Hurkadli et al. [39] also used GnRH antagonists (GnRH-I antagonist: cetrorelix, GnRH-II antagonist: trptorelix) and measured the intracellular calcium concentrations. They observed that trptorelix, but not cetrorelix, completely inhibited the increase of GnRH-IIinduced intracellular calcium concentration. Concurrently, at high concentrations, trptorelix and cetrorelix inhibited the increase of GnRH-I-induced intracellular calcium concentration, whereas at low concentrations they provoked an agonistic action, inducing calcium influx. High concentrations of trptorelix, but not cetrorelix, induced prostate cancer cell death, probably through an apoptotic process caused by a depletion of the internal calcium pool. These very promising observations could lead to the future development of new drugs that can be used in second-line treatments of hormonerefractory prostate cancer.

\section{Novel Approaches in Prostate Cancer}

Even in 2009, treatment options for androgen-refractory disease are still limited and new therapy modalities for this disease is needed. Several investigational drugs in preclinical and early clinical trials have been designed to address this potential mechanism of resistance to ADT which might be mediated by androgen-receptor (AR) signaling.

MDV3100 is a small-molecule, pure AR antagonist that inhibits AR nuclear translocation and DNA binding. Xenograft models have demonstrated significant reductions in cancer volume with MDV3100 in comparison with bicalutamide monotherapy, which showed no effect [40]. Recently presented results of phase I-II studies in humans showed significant PSA reductions in 13 of 14 patients with castration-resistant prostate cancer (CRPC) who were treated for over 4 weeks with MDV3100. The drug was well tolerated, and no clinical or radiographic progression was noted in the 6 patients who were observed for 14 weeks [41].

CYP17A1 is a rate-limiting enzyme in androgen biosynthesis. Inhibition of enzymatic activity at two sequential steps in the androgen biosynthesis pathway leads to reduced dehydroepiandrosterone and androstenedione synthesis, which limits subsequent conversion to testosterone and DHT. Given the key role of CYP17A1 in androgen production, inhibition of this enzyme would be expected to suppress androgen production in all endocrine organs, including the testis, adrenal glands, and postulated tumoral sites of androgen production [42]. Novel CYP17 inhibitors, including ketoconazole, abiraterone acetate, and VN/124-1 are agents currently at different stages of development.

Ketoconazole has been in use as a second line therapy in advanced or metastatic castration resistant prostate cancer. A small retrospective analysis to evaluate the activity of ketoconazole in patients with castration-resistant metastatic prostate cancer has shown activity in patients with docetaxelrefractory disease. With ketoconazole treatment, 4 of 11 (36\%; 95\% CI 8-65\%) patients achieved a 50\% posttreatment decline in PSA including three of four patients who did not achieve a 50\% PSA decline with prior docetaxel [43]. Another phase II study was designed to assess responses to ketoconazole in combination with type I and II 5alpha-reductases (dutasteride) in patients with CRPC. PSA response rate $(>/=50 \%$ decline) was $56 \%$ (32 of $57 ; 95 \% \mathrm{CI}$, 42.4-69.3\%); the median duration of response was 20 months. In patients with measurable disease, $30 \%$ responded by the Response Evaluation Criteria in Solid Tumors. Median time to progression was 14.5 months which was substantially longer compared to previous studies with ketoconazole alone. Testosterone by $66 \%$, and dihydrotestosterone declined to below detectable levels compared with baseline levels with testicular suppression alone [44].

Abiraterone acetate is an orally administered, specific inhibitor of CYP17A1 that has been evaluated in a phase I trial of patients with metastatic CRPC who had undergone multiple hormonal manipulations before enrollment [45]. Significant clinical activity was noted, with PSA reductions of at least $50 \%$ occurring in $57 \%$ of patients, and symptomatic and radiographic improvement documented in some 
cases. Another exciting drug in preclinical evaluation is VN124-1 which combines the advantages of CYP17A1 inhibition, AR antagonism and reduced AR protein synthesis. In vitro models have demonstrated potent $\mathrm{AR}$ antagonism in binding assays and inhibition of CYP17A1 enzymatic activity, while in vivo xenograft models have shown reduced tumor burden in mice treated with VN 124-1 versus those undergoing castration or bicalutamide monotherapy [46]. Suppression of AR protein synthesis-an additional mechanism of action that might prevent resistance developing through AR amplification was also demonstrated both in vitro and in vivo.

The relatively high response rates to the CYP17A1 inhibitor abiraterone acetate and the AR antagonist MDV3100 in patients with CRPC supports the hypothesis that tumoral androgen synthesis and continued AR signaling have a role in the pathogenesis of CRPC $[42,47]$.

\section{CONTROVERSIES IN ADT}

There are some controversies that exist in ADT which are related to the:

- Role of combining ADT with antiandrogens

- Intermittent androgen suppression (IAS)

- Antiandrogen monotherapy

\section{A. Combined Androgen Blockade}

Despite medical or surgical castration, continued release of androgens may occur at low levels mainly from the adrenals. Therefore there is a debate on the use of combined androgen blockade (CAB), which is treatment with castration (GnRH-A or orchiectomy) along with an androgen receptor antagonist. Several randomized studies have compared the use of castration alone versus CAB. An earlier study comparing daily injections of $\mathrm{GnRH}-\mathrm{A}$ versus $\mathrm{CAB}$ found survival benefit in $\mathrm{CAB}$ [48]. However, a second large, randomized study has failed to demonstrate the survival benefit with $\mathrm{CAB}$ when surgical castration was used [49]. A meta-analysis of 27 randomized trials found a $2.9 \%$ survival advantage in 5-years in patients treated with $\mathrm{CAB}$ [50]. It also seemed clear from the meta-analysis that, whereas combined use of nonsteroidal antiandrogens with GnRH-A provided a significant benefit compared to GnRHA alone, combined use of steroidal antiandrogens with GnRH-A seemed to be detrimental, leading to decreased survival rates [50]. It should be noted that bicalutamide was not analyzed in those studies.

Later on, the guidelines have been revised to clearly recommend 'consideration of MAB using bicalutamide' on the basis of one randomized clinical trial and one analytical research study [51-53]. The data quoted for the 2006 ASCO guidelines are results of interim analysis [53] (median follow-up of 66 weeks) of a multicenter, randomized, placebocontrolled phase III study comparing MAB group using bicalutamide and GnRH-A alone group for 205 Japanese patients with untreated advanced prostate cancer. Patients received an LHRH agonist and were randomly assigned to bicalutamide $80 \mathrm{mg}$ orally once daily or placebo. At 6 months of follow-up, it was reported that 17 patients $(16.7 \%)$ in the CAB group and $30(29.7 \%)$ in the monotherapy group experienced disease progression $(P=0.016)$. The risk of progression during follow-up was reduced by $54 \%$ in the CAB group relative to the control group (hazard ratio [HR], 0.46; $95 \% \mathrm{CI}, 0.25$ to $0.84 ; P=0.011$ ) [51]. The MAB group was significantly superior in terms of anti-tumor effects, TTP and TTF without increasing toxicity or QOL deterioration. Moreover, according to the final results (median follow-up of 127 weeks) reported by Usami et al. [54], the superiority of the MAB group in terms of TTP and TTF was even more marked than the interim analysis. However, OS and causespecific survival as the secondary endpoints were not significant between the groups because of a lack of death events. Therefore an investigator-initiated follow-up study was carried out. At median follow-up 127 weeks [55], in the MAB group OS was significantly prolonged and reduced diseasespecific mortality by $22 \%$ (95\% confidence interval of hazard ratio: 0.60-0.99). However, it did not reach a significant difference in cause-specific survival, although there was a trend that the MAB group was superior to GnRH-A alone.

\section{B. Intermittent Androgen Suppression (IAS)}

Although the duration of ADT is not standardized, in most algorithms patients are given ADT until PSA becomes undetectable, usually at 6-12 months [56]. Treatment is then stopped and PSA is monitored. Therapy is usually resumed when PSA reaches $50 \%$ of the pretreatment value, or a level between 4-10 ng/ml (some advocate $2.5 \mathrm{ng} / \mathrm{ml}$ ). However, despite a $90 \%$ primary response rate, prostate cancer almost invariably, becomes androgen independent, or at least, partially refractory to ADT with increasing PSA levels, and radiologic and/or symptomatic progression over time; typically 14 to 20 months in the metastatic setting [48, 49]. It has been hypothesized that the cyclic increase in testosterone might delay progression to androgen independence compared to sustained ADT.

The majority of the clinical experience with IAS to date has been in the form of single-institution phase II studies and the design of those studies has varied substantially; for example, employing GnRH-A with or without a nonsteroidal antiandrogen, on-treatment cycles lasting 3-9 months, and different parameters for initiation of subsequent cycles [57].

Phase II studies have prompted large, multicenter, randomized phase III trials comparing IAS with continuous androgen suppression (CAS) [58]. Several trials, including various phase II studies and interim analyses of phase III trials have suggested improvement in terms of QOL, cardiovascular events and osteoporosis, among other benefits, with IAS $[59,60]$. Rates of OS and progression to CRPC seem to be equivalent to those seen with CAS, according to several phase II trials and early phase III data [61]. According to the preliminary results from a phase III trial of 201 patients with biochemical progression who were randomized to IAS versus CAS, no significant differences were noted between groups in TTP to CRPC at a median follow-up of 31 months [62]. Similarly, another phase III trial of 766 patients with locally advanced or metastatic prostate cancer who were randomized to IAS versus CAS showed no difference in OS 
or progression to CRPC at a median follow-up of 51 months [63]. As patients receive IAS drugs at approximately half the rate that they would with continuous treatment, this approach might reduce costs, with equivalent control rates. The final results of several ongoing large phase III trials are eagerly awaited.

\section{Antiandrogen Monotherapy}

Worldwide, 3 types of nonsteroidal antiandrogens are currently available: bicalutamide, flutamide, and nilutamide. Contrary to ADT, nonsteroidal antiandrogen therapy does not reduce the patients' androgen levels and can maintain body composition and QOL status [64]. Therefore, there is an interest in the use of antiandrogen monotherapy as an alternative to ADT.

The largest study, the EPC (Early Prostate Cancer) program [54] has randomized $>8000$ patients with localized or locally advanced prostate cancer to bicalutamide alone versus placebo after they had been treated with surgery or radiation therapy. At a follow-up of $>7$ years, bicalutamide had a positive impact on TTP but was unable to provide any significant survival benefit compared to placebo. Surprisingly, it decreased the survival in localized disease as compared to placebo and there were more bicalutamide related deaths, in locally advanced disease [15]. Therefore, bicalutamide has not been approved, and is not currently recommended for localized prostate cancer. The debate regarding its actual place in locally advanced prostate cancer remains open and highly controversial.

The use of flutamide monotherapy as an alternative to ADT in the advanced disease setting has not been extensively studied in phase III trials, and only two studies have compared flutamide monotherapy with ADT for advanced prostate cancer. Boccon-Gibod et al. [65] reported that patients with metastatic prostate cancer showed similar survival outcomes with flutamide monotherapy and with ADT; however, that study had limited statistical power because only 104 patients were enrolled. The American Society of Clinical Oncology states that monotherapy with a nonsteroidal antiandrogen may be discussed as an alternative to ADT, but steroidal antiandrogens (currently not approved in the United States) should not be offered as monotherapy [51].

\section{CONCLUSIONS}

Androgen deprivation therapy (ADT) is the most widely used systemic treatment for prostate cancer. In contrast to the metastatic prostate cancer, ADT has shown survival benefit in patients receiving local treatment with radiation therapy for high-risk disease. The results of large trials investigating the optimization of primary ADT, the use of novel agents, either as monotherapy or in combination, are eagerly awaited which might improve quality of life, extend survival, overcome the adverse effects and also prevent the development and progression of CRPC.

\section{REFERENCES}

[1] Imamoto T, Suzuki H, Yano M, et al. The role of testosterone in the pathogenesis of prostate cancer. Int J Urol 2008; 15: 472-80. Lin BJ, Chen KK, Chen MT, Chang LS. The time for serum testosterone to reach castrate level after bilateral orchiectomy or oral estrogen in the management of metastatic prostatic cancer. Urology 1994; 43(6): 834-7.

[3] Byar DP, Corle DK. Hormone therapy for prostate cancer: results of the Veterans Administration Cooperative Urological Research Group studies. NCI Monogr 1988; 7: 165-70.

[4] Tammela T. Endocrine therapy of prostate cancer. J Steroid Biochem Mol Biol 2004; 92: 287-295.

[5] Messing E, Manola J, Sarosdy M, et al. Immediate hormonal therapy compared with observation after radical prostatectomy and pelvic lymphadenectomy in men with node positive prostate cancer: results at 10 years of EST 3886. J Urol 2003; 169: 396.

[6] Medical Research Council Prostate Cancer Working Party Investigators Group: Immediate versus deferred treatment for advanced prostatic cancer: initial results of the Medical Research Council Trial. Br J Urol 1997; 79: 235-46.

[7] Bolla M, Collette L, Blank L, et al. Long-term results with immediate androgen suppression and external irradiation in patients with locally advanced prostate cancer (an EORTC study): a phase III randomized trial. Lancet 2002; 360(9327): 103-6.

[8] Bolla M, Gonzalez D, Warde P, et al. Improved survival in patients with locally advanced prostate cancer treated with radiotherapy and goserelin. N Engl J Med 1997; 337(5): 295-300.

[9] Sharifi N, Gulley JL, Dahut WL. Androgen deprivation therapy for prostate cancer. JAMA 2005; 294: 238-44.

[10] Bubley GJ, Carducci M, Dahut W, et al. Eligibility and response guidelines for phase II clinical trials in androgen- independen prostate cancer: recommendations from the Prostate Specific Antigen Working Group. J Clin Oncol 1999; 17: 3461-7.

[11] Oefelein MG, Feng A, Scolieri MJ, Ricchiutti D, Resnick MI. Reassessment of the definition of castrate levels of testosterone: implications for clinical decision making. Urology 2000; 56: 10214.

[12] Loprinzi CL, Michalak JC, Quella SK, et al. Megestrol acetate for the prevention of hot flashes. N Engl J Med 1994; 331: 34752.

[13] Smith MR, McGovern FJ, Zietman AL, et al. Pamidronate to prevent bone loss during androgen- deprivation therapy for prostate cancer. N Engl J Med 2001; 345: 948- 55.

[14] Smith MR, EasthamJ, Gleason DM, Shasha D, Tchekmedyian $\mathrm{S}$, Zinner N. Randomized controlled trial of zoledronic acid to prevent bone loss in men receiving androgen deprivation therapy for nonmetastatic prostate cancer. J Urol 2003; 169: 2008-12.

[15] Seidenfeld J, Samson DJ, Hasselblad V, et al. Single-therapy androgen suppression in men with advanced prostate cancer: a systematic review and meta-analysis. Ann Intern Med 2000; 132: 566-77.

[16] Morote J, Planas J, Raventos CX, et al. Redefining clinically significant castration levels in patients with prostate cancer receiving continuous androgen deprivation therapy. J Urol 2007; 178: 1290-5.

[17] Denmeade SR, Tombal B, Isaacs JT. Apoptotic Pathways in Prostate Cancer. In: Mattson MP, Estus S, Rangnekar VM, Eds. Programmed cell death. Amsterdam: Elsevier Sciences 2001; Vol. II: pp. 23-54.

[18] McLeod D, Zinner N, Tomera K, et al. A phase 3, multicenter, open-label, randomized study of abarelix versus leuprolide acetate in men with prostate cancer. Urology 2001; 58: 756-61.

[19] Morote J, Esquena S, Abascal JM, et al. Failure to maintain a suppressed level of serum testosterone during long-acting depot luteinizing hormone-releasing hormone agonist therapy in patients with advanced prostate cancer. Urol Int 2006; 77: 135-8.

[20] Jocham D. Leuprorelin three-month depot in the treatment of advanced and metastatic prostate cancer: long-term follow-up results. Urol Int 1998; 60(Suppl 2):18-24.

[21] Khan MS, O'Brien A. An evaluation of pharmacokinetics and pharmacodynamics of leuprorelin acetate 3M-depot in patients with advanced and metastatic carcinoma of the prostate. Urol Int 1998; 60: 33-40.

[22] Fontana D, Mari M, Martinelli A, et al. 3-month formulation of goserelin acetate ('Zoladex' 10.8-mg depot) in advanced prostate cancer: results from an Italian, open, multicenter trial. Urol Int 2003; 70: 316-20.

[23] Tombal B, Berges R. How good do current LHRH agonists control testosterone? Can this be improved with eligard? Eur Urol Suppl $2005 ; 4: 30-6$ 
[24] Tombal B: Appropriate castration with luteinising hormone releasing hormone (LHRH) agonists: what is the optimal level of testosterone? Eur Urol Suppl 2005; 4: 14-9.

[25] Weight C, Klein EA, Jones JS. Androgen deprivation falls as orchiectomy rates rise after changes in reimbursement in the US medicare population. Cancer 2008; 112: 2195-201.

[26] Shahinia VB, Kuo Y, Freeman J, Orihuela E, Goodwin J. Characteristics of urologists predict the use of androgen deprivation therapy for prostate cancer. J Clin Oncol 2007; 25: 535965.

[27] Chu FM, Jayson M, Dineen MK, et al. A clinical study of $22.5 \mathrm{mg}$ LA-2550: a new subcutaneous depot delivery system for leuprolide acetate for the treatment of prostate cancer. J Urol 2002; 168: 1199203.

[28] Perez MR, Chu FM, Gleason D, et al. A six-month, open-label study assessing a new formulation of leuprolide $7.5 \mathrm{mg}$ for suppression of testosterone in patients with prostate cancer. Clin Ther 2002; 24: 1902-14.

[29] Weckermann D, Harzmann R. Hormone therapy in prostate cancer: LHRH antagonists versus LHRH analogues. Eur Urol 2004; 46: 279-84.

[30] Barmoshe S, Zlotta AR. Pharmacotherapy for prostate cancer, with emphasis on hormonal treatments. Expert Opin Pharmacother 2006; 7(13): 1685-99.

[31] Tomera K, Gleason D, Gittleman M, et al. The gonadotropinreleasing hormone antagonist abarelix depot versus luteinizing hormone releasing hormone agonists leuprolide or goserelin: initial results of endocrinological and biochemical efficacies in patients with prostate cancer. J Urol 2001; 165: 1585-9.

[32] Trachtenberg J, Gittleman M, Steidle C, et al. A Phase III, multicenter, open label, randomized study of abarelix versus leuprolide plus daily antiandrogen in men with prostate cancer. J Urol 2002; 167: 1670-4.

[33] Klotz L, Boccon-Gibod L, Shore ND, et al. The efficacy and safety of degarelix: a 12-month, comparative, randomized, open-label, parallel-group phase III study in patients with prostate cancer. BJU Int 2008; 102: 1531-8.

[34] Princivalle M, Broqua P, White R, et al. Rapid suppression of plasma testosterone levels and tumor growth in the dunning rat model treated with degarelix, a new gonadotropin-releasing hormone antagonist. J Pharmacol Exp Ther 2007; 320: 1113-8.

[35] Tombal B, Iversen P, Van Poppel H, et al. Determining the dose of degarelix for effective therapy of prostate cancer patients as investigated by the Degarelix Study Group. ESMO. Ann Oncol 2006; 17(Suppl 9): (Abstract 461P).

[36] Chen A, Kaganovsky E, Rahimipour S, et al. Two forms of gonadotropin-releasing hormone $(\mathrm{GnRH})$ are expressed in human breast tissue and overexpressed in breast cancer: a putative mechanism for the antiproliferative effect of GnRH by down-regulation of acidic ribosomal phosphoproteins P1 and P2. Cancer Res 2002; 62: 1036-44.

[37] Chen A, Ganor Y, Rahimipour S, et al. The neuropeptides GnRH-II and GnRH-I are produced by human $\mathrm{T}$ cells and trigger laminin receptor gene expression, adhesion, chemotaxis and homing to specific organs. Nat Med 2002; 8: 1421-6.

[38] Mahler C, Verhelst J, Chaban M, Denis L. Prolactin and pituitary gonadotropin values and responses to acute luteinizing hormone releasing hormone $(\mathrm{LHRH})$ challenge in patients having long term treatment with a depot LHRH analogue. Cancer 1991; 67: 557-9.

[39] Hurkadli KS, Sheth AR, Garde SV, Doctor VM, Sheth NA. Immunocytochemical localization of follicle stimulating hormone (FSH) in normal, benign and malignant human prostates. $\mathrm{Br} \mathrm{J}$ Cancer 1990; 61: 225-9.

[40] Sawyers CL, Tran C, Wongvipat J, et al. Characterization of a new antiandrogen MDV-3100 effective in preclinical models of hormone refractory prostate cancer. Presented at the ASCO 2007 Prostate Cancer Symposium. Orlando, FL, USA February 22-24, 2007; [abstract \#48].

[41] Scher HI, Beer TM, Higano CS, et al. Phase I/II study of MDV3100 in patients with progressive castration-resistant prostate cancer (CRPC). J Clin Oncol 2008; 26(Suppl 15): [abstract \#5006].

[42] Reid AHM, Attard G, Barrie E, et al. CYP17 inhibition as a hormonal strategy for prostate cancer. Nat Clin Pract Urol 2008; 5: 610-20.
[43] Galsky MD, Simon K, Sonpavde G, et al. Ketoconazole retains activity in patients with docetaxel-refractory prostate cancer. Ann Oncol 2009; 20(5): 965-6.

[44] Taplin ME, Regan MM, Ko YJ, et al. Phase II Study of Androgen Synthesis Inhibition with Ketoconazole, Hydrocortisone, and Dutasteride in Asymptomatic Castration-Resistant Prostate Cancer. Clin Cancer Res 2009; 15(22): 7099-105.

[45] Pravettoni A, Mornati O, Martini PGV, et al. Estrogen receptor beta (ERbeta) and inhibition of prostate cancer cell proliferation: studies on the possible mechanism of action in DU145 cells. Mol Cell Endocrinol 2007; 263: 46-54.

[46] Vasaitis T, Belosay A, Schayowitz A, et al. Androgen receptor inactivation contributes to antitumor efficacy of $17 \alpha$-hydroxylase/ 17,20-lyase inhibitor 3 $\beta$-hydroxy-17-(1H-benzimidazole-1-yl)androsta5,16-diene in prostate cancer. Mol Cancer Ther 2008; 7: 234857.

[47] Attard G, Reid AHM, Yap TA et al. Phase I clinical trial of a selective inhibitor of CYP17, abiraterone acetate, confirms that castration-resistant prostate cancer commonly remains hormone driven. $\mathrm{J}$ Clin Oncol 2008; 26: 4563-71.

[48] Crawford ED, Eisenberger MA, McLeod DG, et al. A controlled trial of leuprolide with or without flutamide in prostatic carcinoma. N Engl J Med 1989; 321: 419-24.

[49] Eisenberger MA, Blumenstein BA, Crawford ED, et al. Bilateral orchiectomy with or without flutamide for metastatic prostate cancer. N Engl J Med 1998; 339: 1036-42.

[50] Prostate Cancer Trialists' Collaborative Group. Maximum androgen blockade in advanced prostate cancer: an overview of the randomized trials. Lancet 2000; 355: 1491-8.

[51] Loblaw DA, Virgo KS, Nam R, et al. Initial Hormonal Management of Androgen-Sensitive Metastatic, Recurrent, or Progressive Prostate Cancer: 2007 Update of an American Society of Clinical Oncology Practice Guideline. J Clin Oncol 2007; 25: 1596-605.

[52] Mulrow C, Langhome P, Grimshaw J. Integrating heterogeneous pieces of evidence in systematic reviews. Ann Intern Med 1997; 127: 989-95.

[53] Akaza H, Yamaguchi A, Matsuda T, et al. Superior anti-tumor efficacy of bicalutamide $80 \mathrm{mg}$ in combination with a luteinizing hormone-releasing hormone (LHRH) agonist versus LHRH agonist monotherapy as first-line treatment for advanced prostate cancer: interim results of a randomized study in Japanese patients. Jap $\mathbf{J}$ Clin Oncol 2004; 34: 20-8.

[54] Usami M, Akaza H, Arai Y, et al. Bicalutamide 80.mg combined with a luteinizing hormone releasing hormone agonist (LHRH-A) versus LHRH-A monotherapy in advanced prostate cancer: findings from a phase III randomized, double-blind, multi-center trial in Japanese patients. Prostate Cancer Prostatic Dis 2007; 10: 194201.

[55] Hinotsu S, Akaza H, Usami M, et al. Combined androgen blockade (CAB) with bicalutamide and a luteinizing hormone-releasing hormone agonist (LHRH-A) versus LHRH-A monotherapy in Japanese patients with advanced prostate cancer: long-term followup reporting overall and cause-specific survival. In: First European Multidisciplinary Meeting on Urological Cancers 2007; [abstract 119].

[56] Grossfeld GD, Small EJ, Lubeck DP, et al. Androgen deprivation therapy for patients with clinically localized (stages T1 to T3) prostate cancer and for patients with biochemical recurrence after radical prostatectomy. Urology 2001; 58(2 Suppl 1): 56-64.

[57] Wright JL, Higano CS, Lin DW. Intermittent androgen deprivation: clinical experience and practical applications. Urol Clin North Am 2006; 33: 167-79.

[58] Bhandari MS, Crook J, Hussain M. Should intermittent androgen deprivation be used in routine clinical practice? J Clin Oncol 2005; 23: 8212-8.

[59] Miller K, Steiner U, Lingnau A. Randomized prospective study of intermittent versus continuous androgen suppression in advanced prostate cancer. J Clin Oncol 2007; 25(Suppl 18): [abstract \#5015].

[60] Calais da Silva FM, Calais da Silva FE, Gonçalves F, et al. Five years survival and risk of death in a phase III study of intermittent monotherapy versus continuous combined androgen deprivation $\mathbf{J}$ Clin Oncol 2008; 26(Suppl 15): [abstract \#16034].

[61] Boccon-Gibbod L, Hammerer P, Madersbacher S, et al. The role of intermittent androgen deprivation in prostate cancer. BJU Int 2007; 100: $738-43$. 
[62] Tunn U, Kurek R, Keinle E, et al. Intermittent is as effective as continuous androgen deprivation in patients with PSA relapse after radical prostatectomy. J Urol 2004; 171(Suppl 4): [abstract \#1458].

[63] Calais da Silva FM, Calais da Silva FE, Bono A, et al. Phase III intermittent MAB vs continuous MAB. J Clin Oncol 2006; 24(Suppl 18): [abstract \#4513].
[64] Iversen P. Quality of life issues relating to endocrine treatment options. Eur Urol 1999; 36(Suppl 2): 20-6.

[65] Boccon-Gibbod L. Are non-steroidal anti-androgens appropriate as monotherapy in advanced prostate cancer? Eur Urol 1998; 33: 15964

Received: June 14, 2009

Revised: December 19, 2009

Accepted: December 19, 2009

(C) Bayraktar and Abdel-Wahab; Licensee Bentham Open.

This is an open access article licensed under the terms of the Creative Commons Attribution Non-Commercial License (http://creativecommons.org/licenses/ by-nc/3.0/) which permits unrestricted, non-commercial use, distribution and reproduction in any medium, provided the work is properly cited. 